\title{
REMOÇÃO DE MACRONUTRIENTES POR ESPÉCIES ORNAMENTAIS CULTIVADAS EM SAC COM APLICAÇÃO DE ÁGUA RESIDUÁRIA
}

\author{
Ana Paula Ferreira Colares ${ }^{1}$ \\ Victória Viana Silva ${ }^{2}$ \\ Rodrigo Nogueira Martins ${ }^{3}$ \\ Viktor Kayro Souza Santos ${ }^{4}$ \\ Juciara Oliveira Lopes ${ }^{5}$ \\ Danilo Pereira Ribeiro ${ }^{6}$
}

Resumo: Este trabalho foi realizado com o objetivo de avaliar a remoção de macronutrientes na água residuária da suinocultura em sistema de tratamento do tipo alagado construído (SAC), cultivado com espécies ornamentais. Oito espécies foram cultivadas, conhecidas popularmente como: aspargo, cambará, cana índica, coração roxo, dinheiro em penca, exória mini, caladium poá e onze horas, plantadas em um SAC preenchido com brita zero. O SAC foi dividido em 5 blocos ao longo de seu comprimento, tendo $2 \mathrm{~m}$ cada bloco, sendo cultivado um exemplar de cada espécie por bloco. As eficiências médias de remoções de Nitrogênio Total Kjeldhal (NTK) e fósforo total (P) foram de 97,7\% e 35,4\%, respectivamente. Dentre os elementos analisados o potássio $(\mathrm{K})$ e sódio $(\mathrm{Na})$, apresentaram as menores médias de remoção, sendo $10,4 \%$ e $3,7 \%$, respectivamente. Com o cultivo diversificado de espécies ornamentais em SAC, com apenas 4 plantas por $\mathrm{m}^{2}$, apesar do melhor aspecto visual da estação de tratamento, no efluente tratado constatouse elevada remoção de Nitrogênio Total Kjeldhal, mas as eficiências de remoção de $P, K$ e Na foram baixas. Palavras-chave: Jardins filtrantes; Uso de esgotos; Paisagismo.

\footnotetext{
${ }^{1}$ Engenharia Agrícola e Ambiental/Instituto Federal do Norte de Minas Gerais, - IFNMG Campus Januária, Brasil. E-mail: anapaula.colares@hotmail.com.

2 Engenharia Agrícola e Ambiental/Instituto Federal do Norte de Minas Gerais, - IFNMG Campus Januária, Brasil. E-mail: victoria.viana.s@gmail.com.

${ }^{3}$ Engenharia Agrícola e Ambiental/Instituto Federal do Norte de Minas Gerais, - IFNMG Campus Januária, Brasil. E-mail: rodrigonmartins@hotmail.com.

${ }^{4}$ Engenharia Agrícola e Ambiental/Instituto Federal do Norte de Minas Gerais, - IFNMG Campus Januária, Brasil. E-mail: viktorpel@hotmail.com.

${ }^{5}$ Engenharia Agrícola e Ambiental/Instituto Federal do Norte de Minas Gerais, - IFNMG Campus Januária, Brasil. E-mail: juciaraoliveiralopes@yahoo.com.br.

${ }^{6}$ Dr. Engenharia Agrícola/Instituto Federal do Norte de Minas Gerais, Brasil. E-mail: danilo.ribeiro@ifnmg.edu.br.
} 